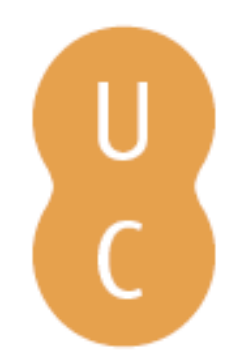

\title{
pommalina
}

\section{Localização estruturada de termiteiras macrotermes pela presença de pegmatitos}

Autor(es): $\quad$ Pereira, C. S. Dias; Gomes, C. A. Leal

Publicado por: Imprensa da Universidade de Coimbra

URL

persistente: $\quad$ URI:http://hdl.handle.net/10316.2/31461

DOI: $\quad$ DOI:http://dx.doi.org/10.14195/978-989-26-0531-9_29

Accessed : $\quad$ 26-Apr-2023 06:33:56

A navegação consulta e descarregamento dos títulos inseridos nas Bibliotecas Digitais UC Digitalis, UC Pombalina e UC Impactum, pressupõem a aceitação plena e sem reservas dos Termos e Condições de Uso destas Bibliotecas Digitais, disponíveis em https://digitalis.uc.pt/pt-pt/termos.

Conforme exposto nos referidos Termos e Condições de Uso, o descarregamento de títulos de acesso restrito requer uma licença válida de autorização devendo o utilizador aceder ao(s) documento(s) a partir de um endereço de IP da instituição detentora da supramencionada licença.

Ao utilizador é apenas permitido o descarregamento para uso pessoal, pelo que o emprego do(s) título(s) descarregado(s) para outro fim, designadamente comercial, carece de autorização do respetivo autor ou editor da obra.

Na medida em que todas as obras da UC Digitalis se encontram protegidas pelo Código do Direito de Autor e Direitos Conexos e demais legislação aplicável, toda a cópia, parcial ou total, deste documento, nos casos em que é legalmente admitida, deverá conter ou fazer-se acompanhar por este aviso. 



\title{
LOCALIZAÇÃO ESTRUTURADA DE TERMITEIRAS MACROTERMES PELA PRESENÇA DE PEGMATITOS
}

\section{INFLUENCE OF PEGMATITES IN THE DISTRIBUTION OF MACROTERMES TERMITE MOUNDS}

\author{
C. S. Dias Pereira ${ }^{1} \&$ C. A. Leal Gomes ${ }^{2}$
}

\begin{abstract}
Resumo - A relação simbiótica que as térmitas Macrotermes estabelecem com o fungo Termitomyces obriga-as a manter condiçóes específicas de humidade, $\mathrm{CO}_{2}$ e temperatura, no interior da termiteira. Deste modo, o seu sucesso reprodutivo, e até a sua sobrevivência, dependem fortemente da disponibilidade de água e argilas no meio. Os pegmatitos e, em especial, as cavidades miarolíticas, possuem argilas e favorecem a circulação e concentração de água, assumindo-se como locais propícios à instalação de colónias deste tipo de insetos. Com este trabalho pretende-se sistematizar a informação obtida até ao momento sobre a localização geologicamente estruturada de edifícios contruídos pelas Macrotermes.
\end{abstract}

Palavras-chave - prospeção, pegmatitos, termiteiras.

Abstract - The symbiotic relations that Macrotermes termites establish with the fungus Termitomyces requires specific conditions of humidity, $\mathrm{CO}_{2}$ and temperature within the termite mound. Thus, the reproductive success and survival depends greatly on the availability of water and clays in the surrounding litologies. The pegmatites, in particular miarolitic cavities, possess clays and allow the movement and concentration of water, being potential sites for the installation of colonies of such insects. This work aims to systematize the information obtained about the influence of pegmatites in the distribution of Macrotermes termite mounds.

Keywords - exploration, pegmatites, termite-mounds.

${ }^{1}$ CIG-R- Departamento de Ciências da Terra - Escola de Ciências - Universidade do Minho; celiasdias@ gmail.com

${ }^{2}$ Departamento de Ciências da Terra - Escola de Ciências - Universidade do Minho; caal.gomes@ gmail.com 


\section{1 - Introdução}

As térmitas pertencentes ao género Macrotermes apresentam uma vasta distribuição nas regióes tropicais, colonizando as áreas florestais e de savana, tais como as que existem na Província da Zambézia, Moçambique. Estes insetos sociais necessitam de manter, no interior da termiteira, temperaturas de cerca de $30^{\circ} \mathrm{C}$, humidade perto da saturação e uma baixa concentração de $\mathrm{CO}_{2}$, para assegurar o cultivo do fungo Termitomyces com o qual estabelecem simbiose. A regulação destas condições físico-químicas ocorre a partir da construção e reestruturação constante do edifício habitacional, o que significa que o seu sucesso reprodutivo está fortemente dependente da disponibilidade de água e de argilas no meio envolvente, constituindo condicionantes à sua sobrevivência. Segundo BOYER (1982), elas desaparecem quando o teor de argilas nos horizontes do solo é inferior a $10 \%$ e apresentam uma distribuição muito restrita, colonizando especialmente os locais com substratos caulínicos (LEPRUN \& ROY-NÖEL, 1976).

Depois da revoada (saída das térmitas aladas, após as primeiras chuvas) os reprodutores primários determinam o local onde se localizará o copularium (1º estádio de desenvolvimento da termiteira).

Assegurado um clima favorável, as Macrotermes deverão implantar-se onde o tipo de litologia e as estruturas geológicas existentes proporcionem água e argila suficientes para a sobrevivência e reprodução (DIAS PEREIRA, 2009). Esta distribuiçáo diferencial poderá dever-se ao facto de os reprodutores primários serem capazes de efetuar uma seleção dos locais mais favoráveis para a instalação da colónia ou, em alternativa, pode verificar-se outra hipótese - os reprodutores primários que selecionam os melhores locais, são os únicos que sobrevivem (DIAS PEREIRA \& LEAL GOMES, 2010).

Os pegmatitos e, em especial as cavidades miarolíticas, possuem argilas que as térmitas necessitam para a construção da termiteira. A instalação destes está marcadamente associada a estruturas geológicas que favorecem a circulação e concentração de água freática (falhas, fraturas, contactos geológicos, etc.). Tais aspetos justificam o objetivo do presente trabalho, que procura perceber a correlação entre a distribuição das termiteiras e os tipos de litologias e estruturas geológicas que as acolhem.

A Zambézia é uma região propícia à instalação de colónias de térmitas e onde estão bem representadas as diferentes classes genéticas e geológicas de pegmatitos graníticos, muito em especial nas regióes que foram cobertas por este estudo (DIAS et al., 2006).

\section{2 - Densidade Linear da Implantaçáo de termiteiras Macrotermes}

Com o intuito de conhecer a densidade da distribuição das termiteiras na Zambézia, foram registadas todas as coordenadas de geo-posicionamento por satélite (GPS) correspondentes aos edifícios de Macrotermes observados em trajeto linear até uma distância não superior a $35 \mathrm{~m}$ para cada lado do percurso (A e B da Fig.1).

De acordo com a figural que ilustra dois trajetos efetuados na região do Alto Ligonha, numa distância de aproximadamente $4.5 \mathrm{~km}$, de Nuaparra a Ririca (percurso A), foram registadas 50 termiteiras, enquanto que no percurso B (Murrupoci-Namacotche) observaram-se 120 edificios ao longo de $21 \mathrm{~km}$. Neste registo a incerteza da localização é de $\pm 2 \mathrm{~m}$. 
A fotointerpretação através do Google Earth (versão 6.1.0.5001) permitiu reconhecer um incremento da densidade linear de implantação das termiteiras da Macrotermes sobre os níveis essencialmente anfibólicos de $\mathrm{P}_{2}$ NMam (Fig.1). Os terrenos anfibólicos apresentam, geralmente, uma cobertura vegetal mais densa, espessuras do solo e regolito maiores e foliação penetrativa vestigial mais marcada em análise distanciada, que veicula a escorrência superficial de água e, previsivelmente, o escoamento subterrâneo. Outro aspeto da distribuição sugere maiores concentraçóes de edifícios de térmitas junto de estruturas de cavalgamento que afetam os anfibolitos (Fig.1).

Na Carta Geológica da regiáo, à escala 1:250 000 (Fig.2) pode confirmar-se, principalmente no percurso B, que o aumento de número de termiteiras de Macrotermes acompanha as fácies anfibólicas.
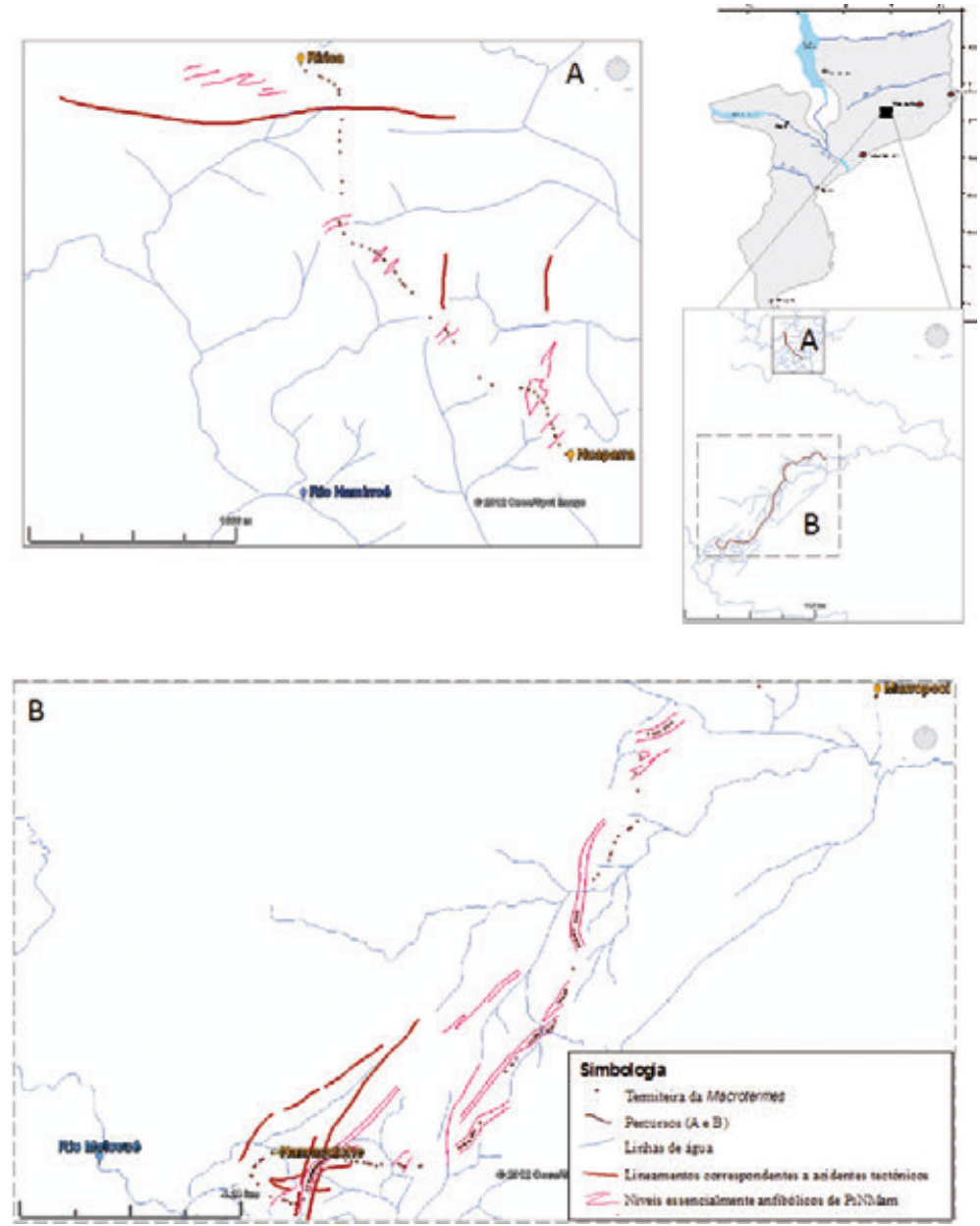

Fig. 1 - Densidade linear da implantação das termiteiras de Macrotermes ao longo de dois percursos (A e B). $\mathrm{P}_{2}$ NMam é a designação de fácies metamórficas anfibólicas consagrada na folha n 1537 (Alto Molocué) da Carta Geológica de Moçambique, à escala 1:250 000 (MACEY et al., 2006). 


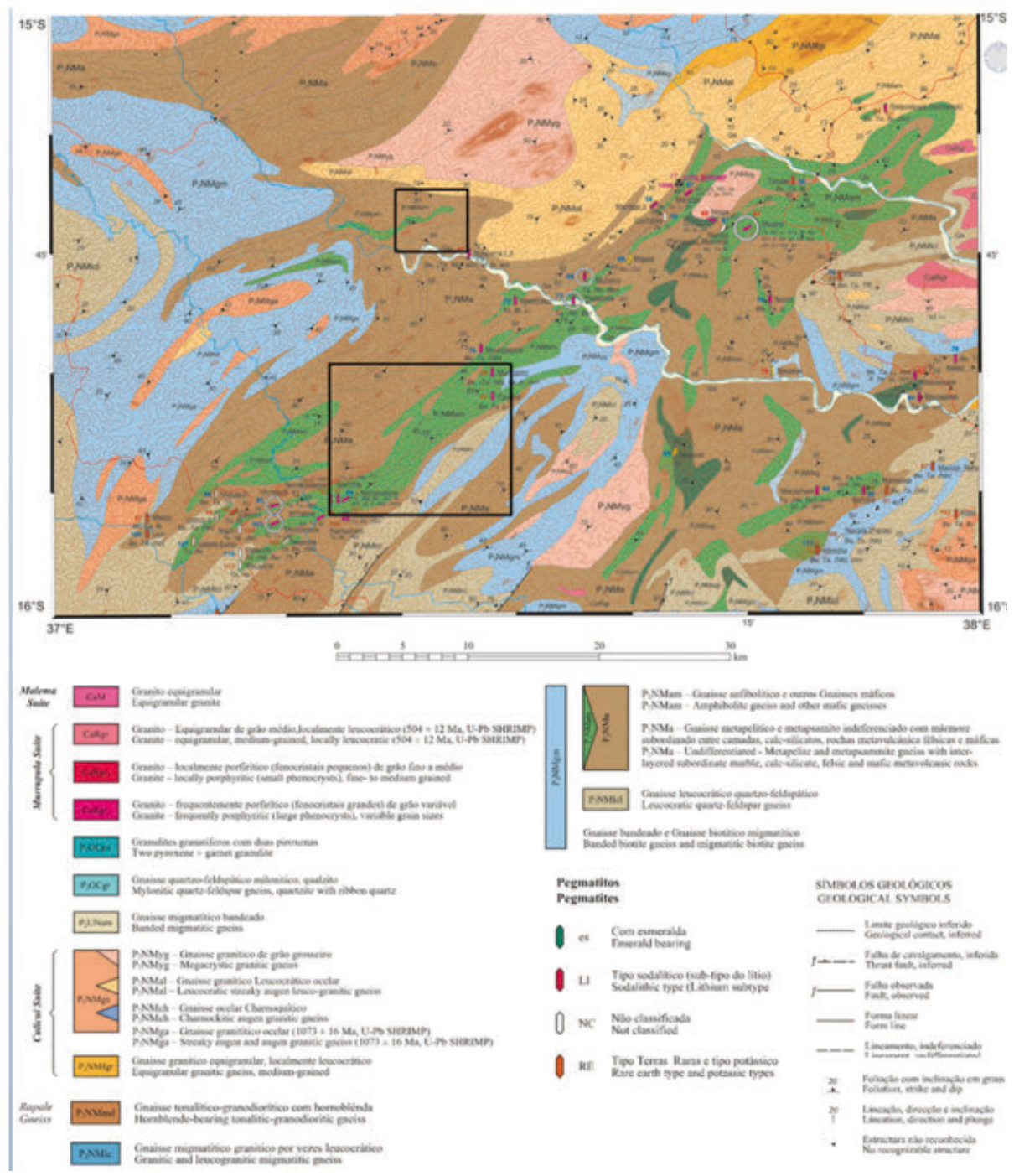

Fig. 2 - Área em estudo, incluída nas folhas no 1537 (Alto Molocué) e no 1538 (Murrupula) da Carta Geológica de Moçambique, à escala 1:250 000 (extrato das folhas originais). Nota: Assinalam-se, com retângulos, os domínios Ririca-Nuaparra, a Norte, e Murrupoci-Namacotche, a Sul, que foram estudados em pormenor.

\section{3 - Localização Estruturada De Termiteiras Macrotermes Pela Presença De Pegmatitos}

O trabalho de campo permitiu, numa constatação de maior detalhe, reconhecer a localização estruturada das termiteiras Macrotermes pela presença de pegmatitos, tendo sido possível definir os quatro tipos de correspondências estruturais que são apresentadas nas figuras $3,4,5$ e 6 . 


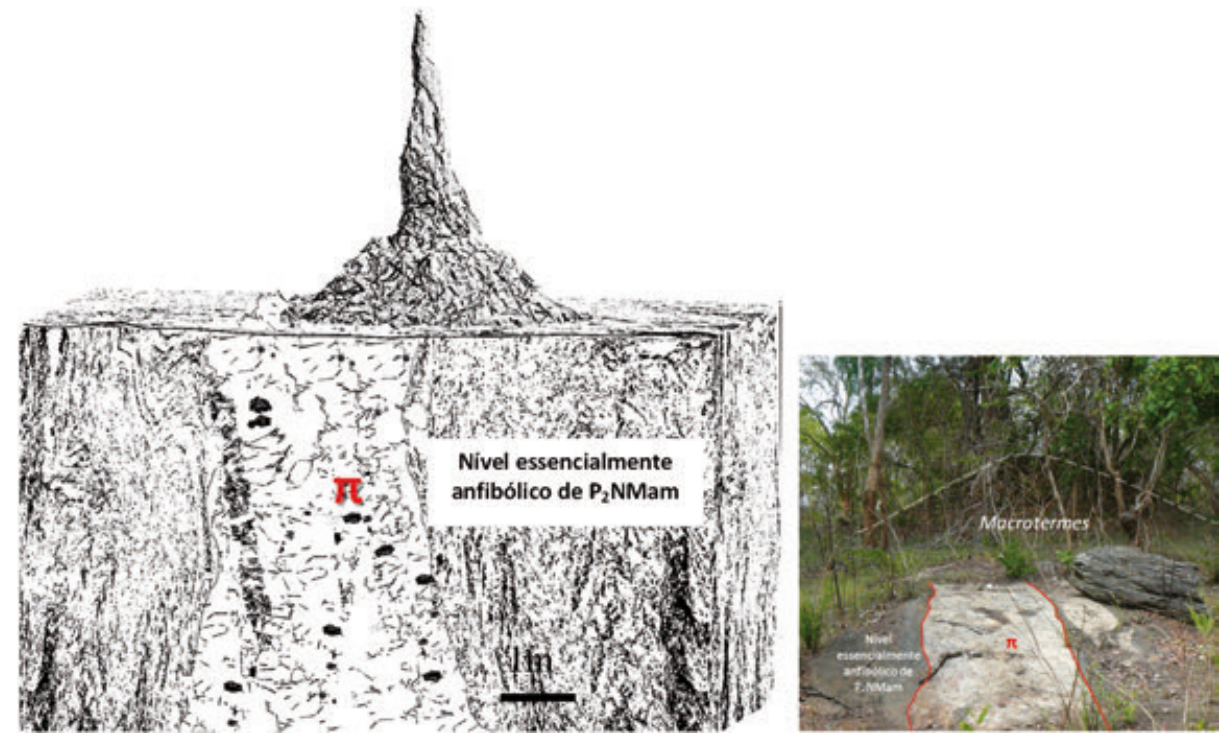

Fig. 3 - Esquema representativo da localização da Macrotermes condicionada pelo contacto entre o pegmatito e as rochas anfibólicas. No lado direito está ilustrado, em fotografia, um exemplo deste tipo de ocorrência, na localidade Maridge, entre Naípa e Nuaparra.

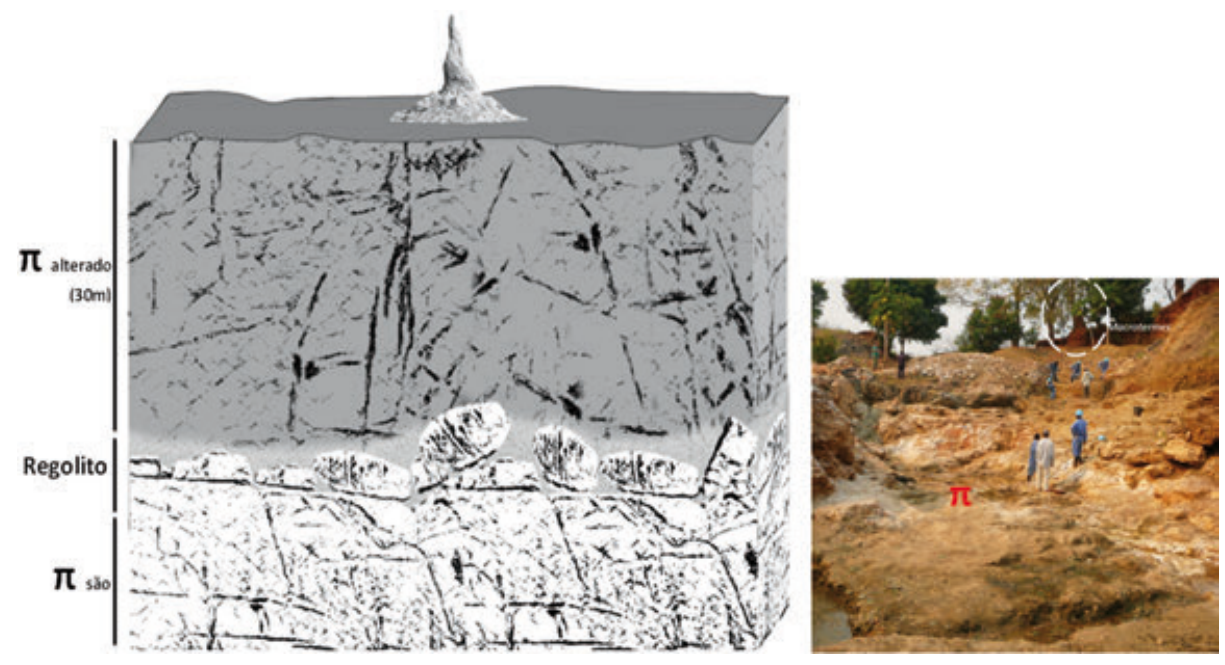

Fig. 4 - Esquema representativo da localizaçáo da Macrotermes condicionada por ruturas existentes em pegmatitos alterados (possivelmente, ruturas primordiais). No lado direito, ilustra-se, em fotografia, um exemplo deste tipo de ocorrência, na exploraçáo mineira de Namacotche. 


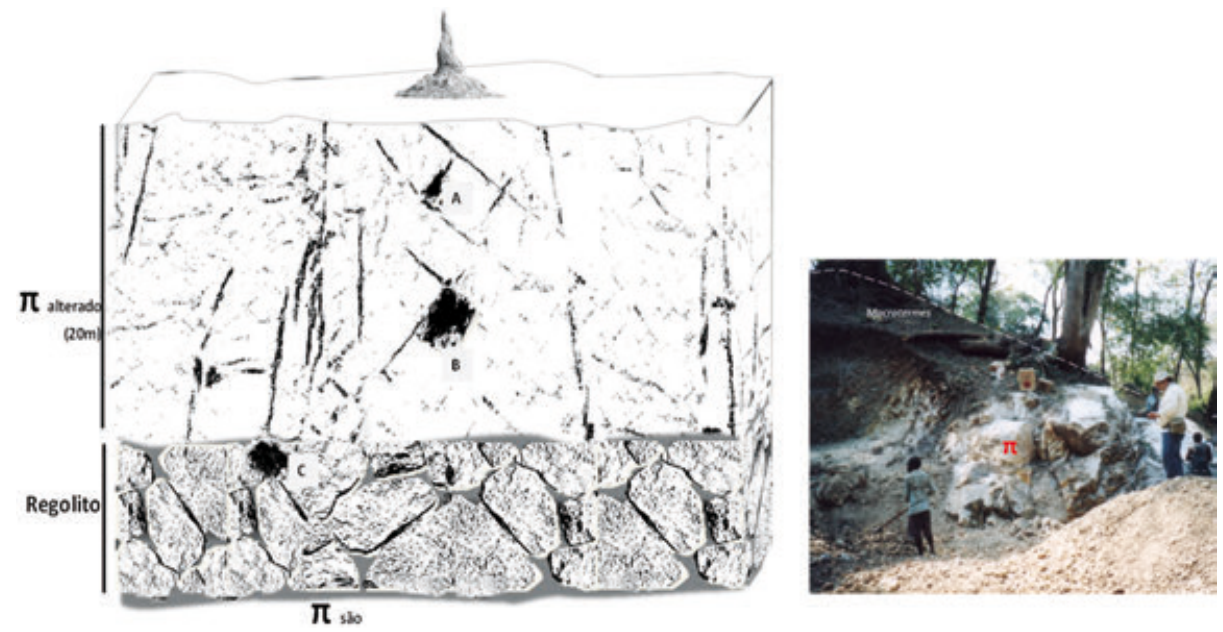

Fig. 5 - Esquema representativo da localização da Macrotermes condicionada por cavidades miarolíticas primárias ou cavidades de corrosão metassomática existentes no pegmatito alterado (A, B e C). No lado direito está ilustrado, em fotografia, um exemplo deste tipo de ocorrência (Iaia-Nahia).
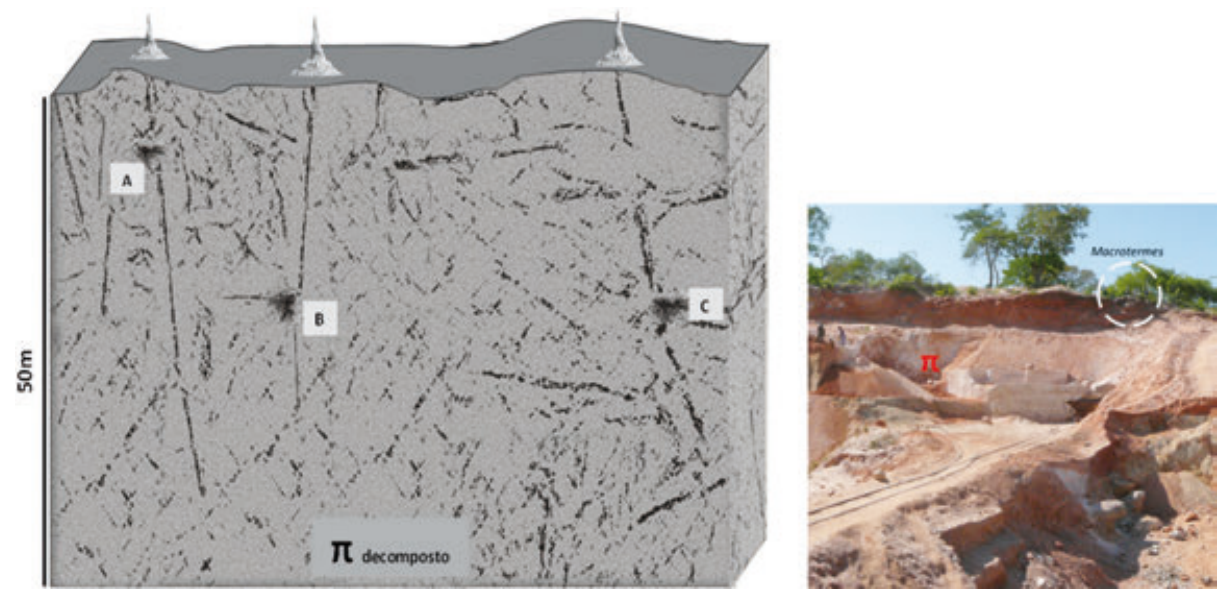

Fig. 6 - Esquema representativo da localização de Macrotermes condicionada por paleoruturas do pegmatito já decomposto. As térmitas aproveitam, muitas vezes, as zonas de incremento de fraturas para instalação do ninho (A, B, C). No lado direito, a fotografia ilustra um exemplo deste tipo de ocorrência (Naípa- sector N da Mina).

\section{4 - Conclusóes}

Do estudo da distribuição linear, em cerca de $25 \mathrm{~km}$ de percurso, pode já perceber-se que existe uma preferência da instalação das Macrotermes em formaçóes anfibólicas - metapelitos, gnaisses e migmatitos com anfíbola e, especialmente, em anfibolitos. Verifica-se uma posição muito marcada entre edificaçôes e heterogeneidades estruturais 
e litológicas observadas nestas formações, sejam elas contactos ou descontinuidades frágeis.

Em afloramento percebe-se que os contactos com os pegmatitos, a presença de cavitaçôes com conteúdo argílico condicionado e as massas pegmatíticas intrusivas em rochas anfibólicas são locais que atraem a instalação dos reprodutivos pioneiros, os quais podem usar as cavidades mais bem definidas como células primárias para desencadear a colonização.

Agradecimentos - O presente trabalho recebeu apoio da FCT através de uma bolsa de doutoramento (SFRH/BD/68562/2010), com cofinanciamento do FSE, do Programa Operacional Potencial Humano/POPH e da União Europeia. O CIG-R é suportado pelo programa Plurianual da Fundação para a Ciência e Tecnologia (FCT), financiado pela União Europeia (programa FEDER) e pelo orçamento nacional da República Portuguesa.

Agradece-se o acolhimento e suporte logístico na realizaçáo dos trabalhos de campo à Empresa Mineira EuroExport (exploração mineira com sede em Nampula, Moçambique). Um agradecimento especial é devido à valiosa ajuda prestada pelos sócios gerentes desta empresa, Sebastian Rosa e José Rosa, e ao supervisor dos trabalhos mineiros.

\section{Referências Bibliográficas}

BOYER, P. (1982) - Quelques aspects de l'action des térmites du sol sur les argiles. Clay Minerals,17, p. 453-462.

DIAS PEREIRA, C. (2009) - Anatomia e mineralogia das edificaçōes de Termitidae da Zambézia (Moçambique): aplicação em prospecção táctica a pontual de jazigos de afinidade pegmatítica. Tese de Mestrado, Universidade do Minho, $103 \mathrm{p}$.

DIAS PEREIRA, C. \& LEAL GOMES, C. (2010) - Localização de cavidades subsuperficiais em regolitos subjacentes de termiteiras da Zambézia - aplicação à prospecção de cavidades miarolíticas em pegmatitos. e-Terra, Geosciences on-line Journal, vol. 20(7). Publication Online - http://metododirecto.pt/CNG2010/ index.php/vol/article/viewFile/439/397 (consultado em 2011.12.12).

DIAS, P. A., LEAL GOMES, C., MARQUES, J. \& GUIMARÃES, F.(2006) - A fraccionação de Bi-Ti-Nb-Ta em pegmatitos graníticos como indicador paragenético para a detecção de água-marinha - Aplicação ao caso de Melatube (Mocuba, Moçambique). VII Congresso Nacional de Geologia.

LEPRUN. J. C. \& ROY-NÖEL J. (1976) - Minéralogie dês argiles et répartition dês nids épigés de deux espéces du genre Macrotermes au Sénégal Occidental (Presqu'ile du Cap-Vert). Insectes Sociaux, 23 (4), p. 535-547.

MACEY, P. H., INGRAM, B. A., CRONWRIGHT, M. S., BOTHA, G. A., ROBERTS, M. R., GRANTHAM, G. H., KOCK, G. S., MARÉ, L. P., BOTHA, P. M. W. \& KOTA, M. (2006) - Carta Geológica 1:250.000, folhas no 1537 e 1538. Direcçáo Nacional de Geologia, Maputo, Moçambique. 